\title{
Analysis of factors influencing deployment of fire suppression resources in Spain using artificial neural networks
}

\author{
Sergi Costafreda-Aumedes ${ }^{(1)}$, \\ Adrian Cardil (2), Domingo $M$ \\ Molina ${ }^{(2)}$, Sarah N Daniel (3), \\ Robert Mavsar ${ }^{(4)}$, Cristina Vega- \\ Garcia (1)
}

\begin{abstract}
In Spain, the established fire control policy states that all fires must be controlled and put out as soon as possible. Though budgets have not restricted operations until recently, we still experience large fires and we often face multiple-fire situations. Furthermore, fire conditions are expected to worsen in the future and budgets are expected to drop. To optimize the deployment of firefighting resources, we must gain insights into the factors affecting how it is conducted. We analyzed the national data base of historical fire records in Spain for patterns of deployment of fire suppression resources for large fires. We used artificial neural networks to model the relationships between the daily fire load, fire duration, fire type, fire size and response time, and the personnel and terrestrial and aerial units deployed for each fire in the period 1998-2008. Most of the models highlighted the positive correlation of burned area and fire duration with the number of resources assigned to each fire and some highlighted the negative influence of daily fire load. We found evidence suggesting that firefighting resources in Spain may already be under duress in their compliance with Spain's current full suppression policy.
\end{abstract}

Keywords: Fire Management, Neural Networks, Regional Models, Suppression Resources, Wildfire

2003 and 2005, Italy in 2007, southeast France in 2003 and 2009 and Greece in 2000, 2007 and 2009 (Cardil et al. 2014). These episodes demonstrate that even strong suppression resources and capabilities may be inadequate when faced, for instance, with extreme fire behavior (Castellnou et al. 2010) or multiple-fire starts linked to human risk (Rachaniotis \& Pappis 2006). The challenges related to wildfires may increase with the predicted climate change, which could intensify fire propagation and increase burned areas, hamper fire suppression operations and increase costs (Raftoyannis et al. 2014), which will be further raised by the expansion of wildland-urban interfaces (WUIs - Liang et al. 2008).

In the Spanish recent past (1998-2009),
(1) Agriculture and Forest Engineering Department, University of Lleida, Alcalde Rovira Roure 191, 25198, Lleida (Spain); (2) Department of Crop and Forest Sciences, University of Lleida, Alcalde Rovira Roure 191, 25198, Lleida (Spain); (3) Agriculture and Environment Department, YMCA-Lebanon, Delta Center, 3rd floor - Horsh Tabet, Sin El Fil, 55570, Beirut (Lebanon); (4) European Forest Institute (EFI), Yliopistokatu 6, 80100 Joensuu (Finland)

@ Cristina Vega-Garcia (cvega@eagrof.udl.es)

Received: Apr 29, 2014 - Accepted: Mar 24, 2015

Citation: Costafreda-Aumedes S, Cardil A, Molina DM, Daniel SN, Mavsar R, Vega-Garcia C (2015). Analysis of factors influencing deployment of fire suppression resources in Spain using artificial neural networks. iForest 9: 138-145. - doi: 10.3832/ifor1329-008 [online 2015-0717]

Communicated by: Davide Ascoli budget was not supposed to be a constraint to forest firefighting. All available firefighting resources were used to minimize the damages, whatever the costs, even if these exceeded any budgetary limit (Vélez 2009). However, budgets are a constraint in the current economic recession (2010-2014), as they will certainly be in the future. For instance, Andalusia decreased its fire suppression budget from $€ 89$ million in 2006 to $€ 77$ million in 2014, and Castile and Leon from $€ 34.4$ million in 2009 to $€ 22.4$ million in 2013 (García-Rey et al. 2014). Consequently, there is a need to examine the amount and patterns of resource use in Spain under the current scenario, because we are already forced to re-think our strategies under rising climateinduced danger, dramatic financial cutbacks and rising values at risk in WUIs.

There are certainly gaps of knowledge in Spain on many suppression-related issues, partly due to a great variability in budgets, operational procedures and social perceptions across the political regions in the country. As agencies responsible for fire management in other countries have aimed to optimize procedures to reduce costs and damages without jeopardizing human safety, a certain amount of work has been devoted to simulating optimal resource allocation and dispatching procedures, mainly for initial attack (Simard \& Young 1978, Islam \& Martell 1998). A comprehensive review may be found in Calkin et al. (2011). Rachaniotis \& Pappis (2006) in Greece addressed the problem of scheduling a single firefighting resource in a multi- 


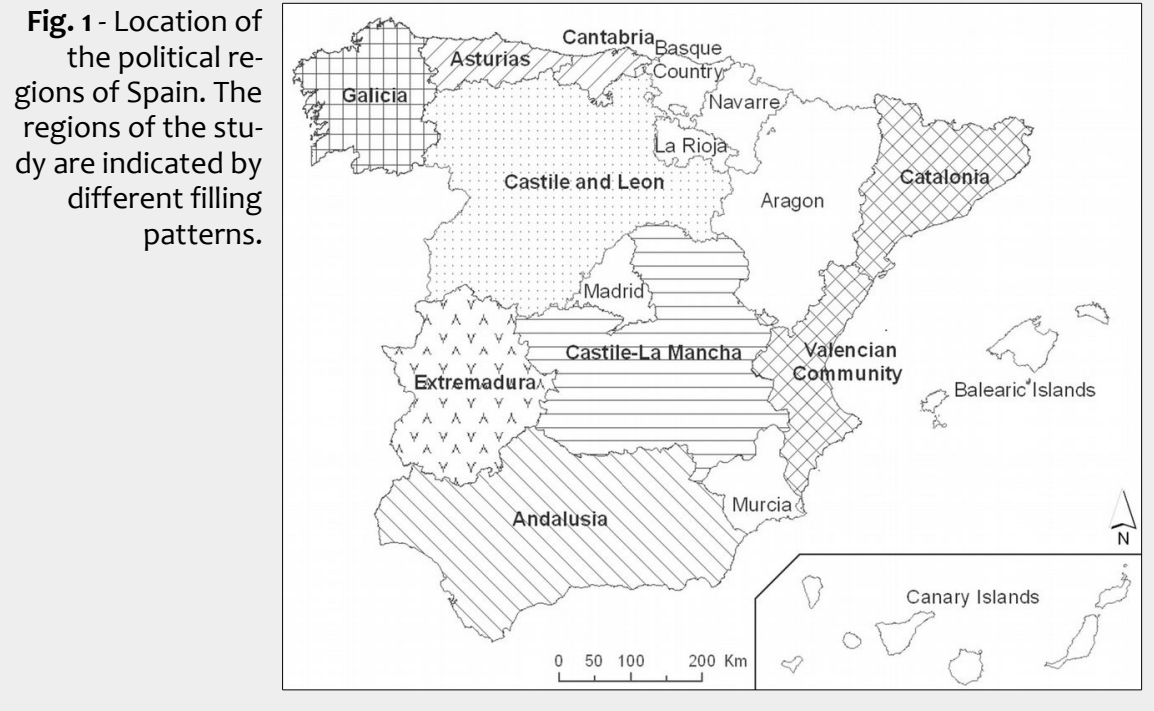

ple-fire situation. Martin-Fernandez et al. (2002) optimized wildfire combat by using simulated annealing and Bayesian global optimization techniques in the Northwest Forest of Madrid (Spain). Rodriguez-Silva (2007) described the SINAMI model for selecting the optimal resource combination for a given fuel type, fire type and duration in Spain. Mendes (2010) used this model to illustrate the application of producer theory and linear programming to optimize suppression.

The anticipated complexity of modeling use of firefighting resources, and the fact that some successful applications had been developed before for other fire problems, led us to select artificial neural networks (ANNs) as a modeling technique. ANNs have been successfully applied to problems such as fire occurrence prediction (Vega-Garcia et al. 1996, Vasconcelos et al. 2001, Li et al. 2009, Vasilakos et al. 2009, Karouni et al. 2014), regional forest fire susceptibility (Dimuccio et al. 2011), forest fire risk prediction and firefighting management in Galicia (Alonso-Betanzos et al. 2003), burned area mapping (Mitrakis et al. 2012), fire-landscape structure relations (Vega-Garcia \& Chuvieco 2006, Ruiz-Mirazo et al. 2012), and the evaluation of forest regeneration after fire (Debouk et al. 2013). ANN models are a reliable alternative to traditional statistical methods because they are robust pattern detectors even for unpredictable non-linear relationships (Scrinzi et al. 2007), they are not affected by multicollinearity or non-normal distributions (Hilbert \& Ostendorf 2001) like statistical techniques, and they are flexible in terms of structure.

In this study, we analyze the main factors influencing fire deployment decisions across Spain, especially the factors behind management decisions when resource limits are pushed during large wildland fires. Models for deployment and containment of large fires have very rarely been explored (Finney et al. 2009). Therefore, we studied fires larger than 100 ha because they cause the most serious problems to fire agencies and society, and because they account for a very high percentage of the total burned area (Cardil \& Molina 2013). Furthermore, in large fires the fire behavior is usually more extreme, and this can influence the risk perception of managers, and hence their deployment decisions (Mills \& Bratten 1988).

All publications cited above were used to identify selected factors that could influence demands on resources in this study. Regarding these factors influencing current deployment decisions across Spain, we aimed to answering the following questions: (i) was the final fire size a major factor in the number of resources involved? (ii) Were more resources used when there was crown fire activity? (iii) Did fire duration influence the amount of resources assigned to fire suppression? (iv) Were enough suppression resources available when simultaneous fires occurred? And finally, (v) if response was not swift enough, did a delayed fire suppression response mean that more resources would be needed later? Deployment of different types of resources to fight fires would be expected to depend on factors such as simultaneous fire occurrence (Rachaniotis \& Pappis 2006) or fire size (Liang et al. 2008). However, the combined influence of these or other factors on fire management remained unknown in the literature, thus justifying this study.

\section{Materials and methods}

\section{Study area}

This study covered the whole area of Spain (17 autonomous communities - Fig. 1) including the Canary and Balearic Islands. Most of the study area is dominated by a Mediterranean climate, and only the northern end has an Atlantic climate. The long summers of high temperatures and low rainfall increase the risk of forest fires in the Mediterranean area. However, even in the northwestern part of Spain, which has an Atlantic climate, forest fire incidence is high (Moreno \& Chuvieco 2002, Vázquez de la Cueva et al. 2006). The different climatic regions, the complex topography and the socio-economic development over millennia resulted in a very uneven spatial distribution of the vegetation, combining the presence of medium-scale farming areas, areas with little natural vegetation cover (grasses and rangelands), extensive shrublands, park-like open forest structures with undergrowth, and high forests of variable densities. Verdu et al. (2012) characterized the relationships between different climatic, topographic and vegetation factors and wildfires in Peninsular Spain.

\section{Historical fire data}

The fire history data used in this study were obtained from the National Wildland Fire Statistics (EGIF) of the Agency for Protection against Forest Fires (ADCIF) of the Spanish Ministry of Environment and Rural and Marine Affairs (MAGRAMA). This national agency is responsible for compiling statistics, supporting regional actions and coordinating fire suppression at national level. However, fire prevention and suppression activities are carried out independently by the 17 autonomous communities.

The data were obtained from standard fire reports, which document each fire and contain information such as starting date and time, response time, fire duration, fire type (surface or crown fire), burned area of forest, shrubland or other land, and number of resources deployed. In our study, data for the period 1998-2008 were considered. It was decided to use only this subset of data because after 1998 the data collection procedures were deeply modified, they are considered generally reliable (Velez 2000), and before 2008 the financial and economic crisis in Spain had not yet affected budgets.

The database underwent many screening and cleaning processes. We discarded all records that contained non-logical information (e.g., records with zero as the fire detection time, zero suppression resources, crown fire type and no wooded burned area, and control time equal to or previous to time of arrival) and records with little information (blanks). The 206978 fire records for the period 1998-2008 were reduced to 170422 fires in our database, and of these we selected all fires larger than 100 ha (10oha+), adding up to 1824 observations for the whole of Spain. The database was later divided for modeling according to regional location in Spain into either separate autonomous communities or combinations of adjacent communities with similar patterns in fire occurrence and suppression, in order to have enough cases for analysis across each territory (Fig. 1). Combined regions were built on the basis of similarity in terms of weather conditions, fire regime and fire social implications, and the existing fire suppression systems (all-in-one emergency agencies or fo- 
rest services). Autonomous communities without neighboring similarities and few large fires (fewer than 100) were discarded for individual models but their data were considered in a general model for the whole of Spain. The rationale for this multiple modeling approach was that we knew that resources differ among regional agencies, but not by how much. Different regions can adjust their resources to their fire problem and values at risk over fire seasons, hence requiring regional models. Those regions with less local suppression resources, though, receive more frequent and intense support from national agencies (the Ministry of Environment and Rural and Marine Affairs, Civil Protection of the Ministry of the Interior, and the Army Emergency Unit). Therefore, we assumed a common baseline in terms of suppression effort across the country for the national model.

\section{Fire suppression resources in the reports: dependent variables}

In the EGIF reports, three main categories of fire suppression resources are listed: personnel (P), terrestrial units (TUs) and aerial units (AUs). The $P$ category includes all different types of personnel that were directly involved in fire suppression: forest and fire supervisors, forest rangers, professional firefighter crews, well-organized volunteer firefighter crews, other civil personnel, police officers, and army personnel. TUs include fire trucks, bulldozers, farm tractors and other heavy machinery used for fire suppression. Finally, AUs include amphibious airplanes, air tankers, suppression helicopters, fire crew helicopters and coordination aircrafts. For each of these groups, only the number of resources deployed is reported in the EGIF dataset.

Though available types of firefighting resources may change with the region, only a number of options are available in the EGIF fire report form, so the closest resource type is usually filled in, thus leading to inaccuracy of the data. Therefore, we only considered the three main categories ( $P$, TUs and AUs) to avoid data noise. The database lacks any information about cost and length (working time) of suppression activities for each group. Therefore, it was impossible to transform suppression resources into one monetary dependent variable. We had to develop models capable of explaining jointly the three dependent variables measured in different units: the quantity of $P$, TUs, and AUs used from each group in each fire.

\section{Individual fire characteristics in the} reports: independent variables

To explore the relationships between individual historical fire (100ha+) observations and their recorded use of suppression resources, a series of independent variables were considered according to the previous literature and our stated goals. The list of the independent variables used in the models (Fire Load, Response Time, Fire Type, Fire Duration and Burned Area), their range of values, their description and their use in previous references are presented in Tab. 1. In selecting these variables we acknowledged that we could not analyze environmental conditions and fire behavior because they were not compiled in the database. These are factors that would influence deployment, firefighting strategies and techniques on-site. However, they are not routinely included in the official reports in Spain. Variables related to vegetation are included in the EGIF database marginally and descriptively, but are not spatially explicit. Weather variables are very limited (days from last rain, temperature, wind speed and direction and relative humidity, just one value for the fire, at only one time), and topography is not present in all the records. Every EGIF fire is classified according to type of fire, but the individual record does not contain information on behavior or spread (intensity, direction, flame length, etc.). Therefore, we selected Fire Type (surface or crown fire, also in the record) as the best proxy variable to account for general fuel and danger conditions in the fire environment.

\section{ANN models}

High correlations should be expected between the variables (e.g., fire duration and fire size). Fire suppression resources would be measured in different units, people, trucks, helicopters or air tankers, which could not be added, but would also be correlated. Multicollinearity and the consideration of different types of suppression resources as joint dependent variables in the same model made the choice of ANN optimal for modeling their use in large fires across Spain.

An ANN is an information processing sys- tem capable of identifying and fitting very complex non-linear patterns by iterative adjustment of the weights or connections between nodes (free parameters to store the relation between variables in the models) organized as input, hidden and output layers. Our models were feed-forward, multilayered, non-linear, fully connected cascade-correlation networks (Fahlman \& Lebiere 1990) built using NeuralWorks Predict ${ }^{\circledR}$ v.3.24 software (NeuralWare 2009). The models were computed as in Alcázar et al. (2008) and Debouk et al. (2013), but with three output nodes (one for each of the suppression dependent variables). With the cascade-correlation method, the architecture of any network is not set beforehand. Training based on an adaptive gradient learning rule - a variant of the general algorithm of back-propagation (Werbos 1994) - started with no hidden layer, and then hidden units were tested and added during the training process, creating an optimal multi-layer structure (Fahlman \& Lebiere 1990) by the time the best possible correlation between observed and predicted suppression variables was achieved.

The independent variables (Fire Load, Response Time, Fire Duration, Fire Type and Burned Area) went through a comprehensive number of transformations (e.g., linear exponential, inverse, tanh, log, power functions), which were tested as possible inputs to the models with a genetic algorithm prior to model building (as in Alcázar et al. 2008). Also previous to model building, the national database of 1824 large fires was split into two subsets: $90 \%$ of the data were used for developing the networks (this sample was further divided into two: $70 \%$ for training and 30\% for periodic testing and assessing of performance accuracy) and 10\% for independent validation (data not used for building the model). To avoid the common problem of losing generalization capacity and the ability to perform well with new data in training a network model, it is customary to apply early stopping with a test set (Guan \& Gertner 1991, Hasenauer et al. 2001, Corne et al. 2004). The database was divided according to regional location in Spain, and separate explanatory models were built for several regions. The regional databases were also split in two subsets: $10 \%$ for validation and 90\% for developing the models (training $70 \%$, testing $30 \%$ ).

For each of the models several replicate

Tab. 1 - List of the independent variables used in our models, value range, description and use in previous references.

\begin{tabular}{|c|c|c|}
\hline Independent variables & Description & Previous references \\
\hline Fire Load (1-169 fires/day) & $\begin{array}{l}\text { The number of fires occurring on the same day and in the } \\
\text { same region }\end{array}$ & $\begin{array}{l}\text { Islam \& Martell (1998), Rachaniotis \& Pappis } \\
\text { (2006) }\end{array}$ \\
\hline Response Time $(0-47.5 \mathrm{~h})$ & Hours between detection and arrival at the fire & Islam \& Martell (1998) \\
\hline Fire Duration $(0-236.5 \mathrm{~h})$ & Hours between detection and control of the fire & $\begin{array}{l}\text { Not used. Conceptually related but not the } \\
\text { same variable }\end{array}$ \\
\hline Fire Type (logical,1.2) & Surface or crown fire (SF, CF) & Mees \& Strauss (1992) \\
\hline Burned Area (100-19190.9 ha) & Wooded, non-wooded area and non-forest area affected & Liang et al. (2008) \\
\hline
\end{tabular}


networks were simulated by changing the random selections of fire observations falling within the validation, test and building datasets. We wanted to check for stability in the resulting models (convergence to the same solution). For each of these replicate networks, at least five different initial starting points (random weights assigned) were set for training, to avoid local minima. Given that some regions had a limited number of fires, a weight decay factor was applied to the learning rule for the corresponding regional models to inhibit the complexity of the models (Hasenauer et al. 2001, NeuralWare 2009). Models for regions with a low number of fires should not have complex networks with many weights or connections, as rules are often applied regarding the number of cases needed per weight for a robust network.

If all the resulting networks (at least 15) converged to a similar result, we considered the solution robust and chose the best net model.

In selecting the best ANN model, we looked for a high Pearson correlation between observed and predicted fire suppression units, low root-mean-square error, balanced results between the three datasets and parsimonious architecture. A sensitivity analysis based on partial derivatives (Jutras et al. 2009) was used to determine which independent variable had the highest impact on the predicted variable, since networks were too complex for direct examination. Finally, the frequency of selection of each independent variable by the generic algorithm in each model was exa- mined. The higher the frequency of the independent variable, the more relevant it was in explaining the dependent variable. The same independent variable might enter any network twice or more times, further emphasizing its importance in the corresponding model (Alcázar et al. 2008).

\section{Results}

The maximum values of the variables were 1833 for P, 173 for TUs, and 43 for AUs. Pearson's correlation between $\mathrm{P}$ and TUs was $0.72,0.67$ for $P$ and Aus, and 0.56 between TUs and AUs $(p<0.01)$. Therefore, the correlation between dependent variables was significant and more personnel implied more aerial and terrestrial units also being used.

Average values of resources used per fire and per burned area (100ha+) for the regions analyzed in Spain are presented in Tab. 2. In relation to the number of resources per fire, Aragon, Catalonia, the Valencian Community and Andalusia had the highest values and Cantabria and Asturias the lowest. Similar results were obtained considering the number of resources $(P$, TUs and AUs) per burned area (Tab. 2). Therefore, noteworthy differences were found among regions in Spain.

No suitable ANN model could be designed for separately modeling Aragon, La Rioja, Madrid, Basque Country, Balearic and Canary Islands due to lack of sufficient data (fewer than 50 cases), so we focused our efforts on the other regional models with higher fire incidence.

Integrated models for the three depen- dent variables ( $P$, TUs and AUs) were successfully built using different combinations of the independent variables Fire Load, Fire Duration, Fire Type and Burned Area. The variable Response Time was discarded early in the development of the models as it showed no significance during any of the building processes. In total, we obtained eight models, one for each of the seven regions and one for the whole of Spain.

General model diagnostics (Pearson's $R$ and network architecture) for the best eight models are presented in Tab. 3, where the network architecture for all the best models is also listed, referring to the number of input, hidden and output nodes. ANN architectures were not too complex, but they were more substantial in Castile and Leon and Cantabria and Asturias, with a larger number of nodes in the hidden layer.

The ANN fittings (Pearson's R) between predicted and observed values of the Spanish model training data were 0.66 for $P$, 0.54 for TUs and 0.59 for AUs, with a 5-11-3 structure. Correlations between predicted and observed values of the Spanish model validation data were 0.70 for $\mathrm{P}, 0.65$ for TUs and 0.60 for AUs.

By regions, Castile and Leon and Galicia showed the most complex architectures (24 nodes in the hidden layer), while the other models had a similar architecture to that of the global model. The best results by regions were obtained in Castile-La Mancha and Castile and Leon ( 0.80 and 0.66 Pearson's $R$ values averaged over the three datasets and resource types) and the

Tab. 2 - Average values for each resource (personnel: P; aerial units: Aus; terrestrial units: TUs) per large fire and per 100 ha burned across regions in Spain, with the corresponding standard deviation. Regions: Castile and Leon (CL); Andalusia (AN); Castile-La Mancha (CM); Catalonia and Valencian Community (CV); Extremadura (EX); Galicia (GA); Cantabria and Asturias (CA).

\begin{tabular}{lccccccc}
\hline Regions & Large Fires $(\mathrm{N})$ & Av.P/F & Av.TUs/F & Av.AUs/F & Av.P/100ha & Av.TUs/100ha & Av.AUs/100ha \\
\hline Spain & 1824 & $110.92 \pm 153.92$ & $9.85 \pm 13.82$ & $5.08 \pm 5.5$ & $41.32 \pm 48.96$ & $3.83 \pm 5.4$ & $2.05 \pm 2.43$ \\
CL & 507 & $90.28 \pm 123.35$ & $7.08 \pm 9.81$ & $3.72 \pm 4.43$ & $34.95 \pm 46.29$ & $2.77 \pm 4.14$ & $1.45 \pm 1.78$ \\
AN & 151 & $233.15 \pm 210.03$ & $12.95 \pm 10.48$ & $10.50 \pm 7.12$ & $84.59 \pm 58.88$ & $5.19 \pm 4.74$ & $4.26 \pm 3.34$ \\
CM & 134 & $112.48 \pm 134.38$ & $11.63 \pm 10.28$ & $5.42 \pm 5.98$ & $39.66 \pm 48.7$ & $4.32 \pm 3.97$ & $1.93 \pm 2.33$ \\
CV & 118 & $277.37 \pm 279.7$ & $33.65 \pm 32.5$ & $10.81 \pm 7.38$ & $80.80 \pm 86.77$ & $10.68 \pm 13.26$ & $3.62 \pm 3.47$ \\
EX & 181 & $82.80 \pm 74.69$ & $7.69 \pm 9.37$ & $3.91 \pm 4.29$ & $34.66 \pm 28.52$ & $3.07 \pm 3.32$ & $1.51 \pm 1.6$ \\
GA & 497 & $66.37 \pm 57.56$ & $7.32 \pm 6.48$ & $4.50 \pm 4.26$ & $29.84 \pm 23.96$ & $3.36 \pm 3.32$ & $2.09 \pm 2.32$ \\
CA & 127 & $27.97 \pm 28.57$ & $1.70 \pm 2.43$ & $1.41 \pm 2.14$ & $13.59 \pm 12.86$ & $0.85 \pm 1.19$ & $0.69 \pm 1.15$ \\
\hline
\end{tabular}

Tab. 3 - General diagnostic with Pearson's R and architecture of the best eight artificial neural network (ANN) models for all autonomous communities and for the whole of Spain for the period 1998-2008. Regions: Castile and Leon (CL); Andalusia (AN); Castile-La Mancha (CM); Catalonia and Valencian Community (CV); Extremadura (EX); Galicia (GA); Cantabria and Asturias (CA).

\begin{tabular}{|c|c|c|c|c|c|c|c|c|c|}
\hline \multirow{2}{*}{$\begin{array}{l}\text { ANN } \\
\text { architecture }\end{array}$} & \multirow{2}{*}{ Set } & Spain & $\mathrm{CL}$ & AN & CM & CV & EX & GA & $\mathrm{CA}$ \\
\hline & & $5-11-3$ & $7-24-3$ & $4-8-3$ & $3-9-3$ & $3-10-3$ & $4-4-3$ & $5-24-3$ & $5-2-3$ \\
\hline \multirow[t]{3}{*}{ Personnel } & Train & 0.662 & 0.637 & 0.809 & 0.744 & 0.588 & 0.700 & 0.662 & 0.428 \\
\hline & Test & 0.699 & 0.508 & 0.805 & 0.773 & 0.779 & 0.582 & 0.560 & 0.685 \\
\hline & Validation & 0.698 & 0.851 & 0.357 & 0.944 & 0.599 & 0.571 & 0.574 & 0.397 \\
\hline \multirow{3}{*}{$\begin{array}{l}\text { Terrestrial } \\
\text { units }\end{array}$} & Train & 0.542 & 0.522 & 0.706 & 0.666 & 0.601 & 0.720 & 0.596 & 0.244 \\
\hline & Test & 0.545 & 0.528 & 0.677 & 0.745 & 0.380 & 0.370 & 0.456 & 0.668 \\
\hline & Validation & 0.651 & 0.808 & 0.412 & 0.908 & 0.505 & 0.733 & 0.395 & 0.740 \\
\hline \multirow[t]{3}{*}{ Aerial units } & Train & 0.594 & 0.567 & 0.741 & 0.784 & 0.494 & 0.616 & 0.513 & 0.323 \\
\hline & Test & 0.606 & 0.628 & 0.706 & 0.739 & 0.483 & 0.641 & 0.448 & 0.447 \\
\hline & Validation & 0.600 & 0.866 & 0.644 & 0.931 & 0.628 & 0.687 & 0.500 & 0.441 \\
\hline
\end{tabular}


Tab. 4 - Interactions between independent and dependent variables in each region and the whole Spain. Values of average sensitivity for the period 1998-2008. Regions: Castile and Leon (CL); Andalusia (AN); Castile-La Mancha (CM); Catalonia and Valencian Community (CV); Extremadura (EX); Galicia (GA); Cantabria and Asturias (CA).

\begin{tabular}{|c|c|c|c|c|c|c|c|c|c|c|}
\hline $\begin{array}{l}\text { ANN } \\
\text { architecture }\end{array}$ & Variables & & Spain & $\mathrm{CL}$ & AN & $C M$ & CV & EX & GA & CA \\
\hline \multirow[t]{5}{*}{ Personnel } & Fire Load & & -1.033 & -0.065 & 0 & 0 & 0 & 0 & -0.208 & -0.006 \\
\hline & Fire Duration & & 0.206 & 0.173 & 0.641 & 0.187 & 0.108 & 0.0005 & 0.263 & 0.337 \\
\hline & Fire Type & Crown & 0.045 & 0.028 & 0 & 0.006 & 0.064 & 0.0561 & 0.035 & 0 \\
\hline & & Surface & 0 & 0 & 0 & 0 & 0 & 0 & 0 & 0.063 \\
\hline & Burned area & & 0.652 & 0.047 & 2.693 & 0.089 & 0.270 & 2.165 & 0.111 & 0.219 \\
\hline \multirow{5}{*}{$\begin{array}{l}\text { Terrestrial } \\
\text { units }\end{array}$} & Fire Load & & -0.802 & -0.079 & 0 & 0 & 0 & 0 & -0.202 & -0.073 \\
\hline & Fire Duration & & 0.061 & -0.114 & 0.598 & 0.279 & -0.070 & 0.0003 & 0.366 & 0.187 \\
\hline & Fire Type & Crown & 0.050 & 0.030 & 0 & 0.053 & 0.102 & 0.0306 & 0.050 & 0 \\
\hline & & Surface & 0 & 0 & 0 & 0 & 0 & 0 & 0 & 0.051 \\
\hline & Burned area & & 0.777 & 0.056 & 3.238 & 0.346 & 0.467 & 10.747 & 0.131 & 0.155 \\
\hline \multirow[t]{5}{*}{ Aerial units } & Fire Load & & -1.344 & -0.104 & 0 & 0 & 0 & 0 & -0.277 & -0.009 \\
\hline & Fire Duration & & 0.512 & 0.855 & 0.848 & 0.372 & 0.121 & 0.0002 & 0.246 & 0.182 \\
\hline & Fire Type & Crown & 0.065 & 0.057 & 0 & 0.004 & 0.082 & 0.0418 & 0.027 & 0 \\
\hline & & Surface & 0 & 0 & 0 & 0 & 0 & 0 & 0 & 0.046 \\
\hline & Burned area & & 0.879 & 0.054 & 5.656 & 0.153 & 0.517 & 2.127 & 0.074 & 0.091 \\
\hline
\end{tabular}

Tab. 5 - Simulation of input-output effects in the model for Spain.

\begin{tabular}{|c|c|c|c|c|c|c|c|c|c|}
\hline Sensitivity & Variable & 巳 & 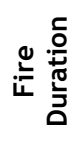 & 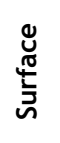 & 克 & 胥 & 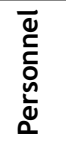 & 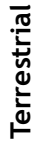 & $\frac{\bar{\sigma}}{\frac{1}{d}}$ \\
\hline \multirow{2}{*}{$\begin{array}{l}\text { Sensitivity } \\
\text { Spain model }\end{array}$} & Avg. Values for Surface Fire & 21 & 20 & 1 & 0 & 301 & 49 & 4 & 2 \\
\hline & Avg. Values for Crown Fire & 23 & 28 & 0 & 1 & 731 & 107 & 9 & 5 \\
\hline \multirow{6}{*}{$\begin{array}{l}\text { Crown fires } \\
\text { sensitivities }\end{array}$} & Avg. Burned Area + 1STD ha & 23 & 28 & 0 & 1 & 2463.2 & 113 & 10 & 6 \\
\hline & Min. Burned Area 100 ha & 23 & 28 & 0 & 1 & 100 & 58 & 4 & 3 \\
\hline & Avg. Values Fire Load +5 fires & 28 & 28 & 0 & 1 & 731 & 102 & 9 & 5 \\
\hline & Avg. Values Fire Load - 5 fires & 18 & 28 & 0 & 1 & 731 & 114 & 10 & 6 \\
\hline & Avg. Fire Duration $+5 \mathrm{~h}$ & 23 & 33 & 0 & 1 & 731 & 111 & 10 & 6 \\
\hline & Avg. Fire Duration $-5 \mathrm{~h}$ & 23 & 23 & 0 & 1 & 731 & 101 & 9 & 5 \\
\hline
\end{tabular}

worst in Cantabria and Asturias (0.49). The average sensitivity indicates the direction of change (Tab. 4) and the factors that influence the number of resources ( $P$, TUs and $\mathrm{AUs}$ ). In order to more accurately illustrate the impact of inputs on outputs, we ran the network model for Spain with average input values for crown or surface Spanish fires, and then we shifted them up and down for crown fires (the most dangerous). The effects of changing Burned Area, and increasing or decreasing Fire Duration and Load ( \pm 5 units) is reported in Tab. 5 .

In the global Spanish model (all the data) the average absolute error was approximately 60 for P, 6 for TUs and 3 for AUs (all similar for training, testing and validation data samples). The variables with the highest weight for the fire suppression resources ( $P$, TUs and AUs) were Fire Load (negative) and Burned Area (positive), followed by Fire Duration and crown Fire Type (both positive). Thus, the number of forest firefighting resources is higher in larger fires when regional fire frequency is low, and in long-duration crown fires.

The average absolute error of the regional models is widely variable, being the highest in Catalonia and the Valencia Community and the lowest in Cantabria and Asturias. The value ranges were $15-135$ for P, 1.5-20 for TUs, and 1.5-5 for AUs. The number of selected variables in each model is uneven, being only two (Fire Duration and Burned Area) for the Andalusian model. The behavior of their variables is similar to the global Spanish model, in which Fire Load was negatively related to the number of resources (or not affecting them), while Fire Duration, Burned Area and crown Fire Type were positive. Thus, the number of resources for extinguishing a fire was greater in large, long duration crown fires, as expected.

Tab. 4 shows some special patterns. In the Cantabria and Asturias region, more firefighting resources were allocated to surface fires than to crown fires. Fire Duration in Castile and Leon was negatively correlated with the number of TUs, and the correlation between Burned Area and TUs and AUs was stronger in Andalusia and Extremadura than in other regions.

\section{Discussion}

Cascade-correlation ANNs were used to model the relationships between suppression resources deployed in large wildland fires (100ha+) and several independent variables (Fire Load, Fire Duration, Fire Type and Burned Area) in Spain. Our models had a similar behavior and architecture, and replicates converged even when observations were randomly shifted in the training, testing and validation datasets.
These findings agree with those of other works (Scrinzi et al. 2007, Alcázar et al. 2008) and indicate that the models were robust and the databases were suitable for identifying the trends in the data through the analysis of input/output relationships. However, it would be advisable to improve the data collected in order to obtain more accurate analyses in the future, including other information than the quantification of resources used by type (e.g., economic information).

As a general observation, modeling of TUs showed slightly worse results than that of AUs and P, and P showed the best prediction accuracy within the same model and across all models. Trends in dispatching TUs could be related to the proximity and accessibility of the TUs to the fire location. Local factors such as distance, access, the presence and steepness of forest roads are instrumental, as Mees \& Strauss (1992) mentioned, and could explain the higher use of TUs in the densely populated eastern and southern Spanish regions in large wildland fires and the lower use in Castile and Leon. Castile and Leon is the largest region in both total area and total forest area, but it has one of the lowest population densities (27 inhabitants per square kilometer).

Different considerations may be applied to $\mathrm{P}$ and AU. According to Ganewatta \& 
Handmer (2009), AUs are only justified when other resources cannot reach the fire site, but in Spain they are routinely used in many cases and scenarios. This means that AU dispatching could also depend on limited access to the fire site by other resources (interaction effects). AU use is usually restricted by weather conditions and geographic or socio-economic factors (Donovan \& Rideout 2003, Gebert et al. 2007, Kaval 2009).

For the general model at the national level, the number of forest firefighting resources is higher in large, crown and long duration fires when regional fire frequency is low. The fire load negatively influenced deployment to large fires, as found in other environments for fire suppression in the USA (Gonzalez-Caban 1986, Donovan \& Rideout 2003). Islam \& Martell (1998) also found an effect of fire load on aerial initial attack range in Ontario. Our findings apparently contradict those of Hunter (1981), who concluded that response time and dispatching decisions were not affected by multiple-fire occurrences in Montana, USA, though the US environment and the forest fire policy greatly differ from the current Spanish situation.

Not surprisingly, at the national level when the burned area increases, the number of dispatched resources increases, as was also found by Liang et al. (2008). The behavior of the independent Fire Type variable seemed to capture the general knowledge that crown fires are the most severe and destructive type of fires (Alexander \& Cruz 2014), thus requiring most suppression resources (Dupuy 2009). The fire duration variable showed that the longer the fire, the more resources would be assigned for suppression activities. However, this was more likely for AUs than for TUs, in agreement with Castellnou et al. (2010). Sensitivity analysis of the national model shows, for instance, that a reduction from average Burned Area in crown fires (731 ha) to the minimum considered in the study of 100 ha saves 49 personnel, 5 machines and 2 aircraft from being deployed. An increase in simultaneous fire occurrence by 5 more fires in the same day and region means that 5 fewer people will be deployed to any crown fire. A delay of 5 hours in controlling a crown fire causes on average an increase of 4 people, one TU and one AU.

Our 7 regional models showed a similar behavior and structure to the national Spanish model, but not all of them achieved equally good results or used the same variables, indicating different regional trends in the use of firefighting resources across Spain. The NW regions (Galicia, Cantabria and Asturias) had lower goodness-of-fit (network Pearson's R correlation) values than central Spain (Castile and Leon and Castile-La Mancha) and the Mediterranean regions (Catalonia and the Valencian Community region). The NW regions also had lower average absolute errors, but this is a consequence of the lower number of resources usually deployed in these regions and not an indication of better model fit.

Regarding Fire Type, in the NW region of Galicia crown fires also appeared to be important for resource deployment, but Fire Load, Fire Duration, and Burned Area (the last one to a lesser extent) were far more influential variables in the best model. The model also confirmed that the influence of fire simultaneity in Galicia is the highest in Spain (Chas-Amil et al. 2010). Also, this NW region was more difficult to model in terms of fire occurrences (Padilla \& Vega-Garcia 2011), indicating that the general fire environment (social and biophysical) and related patterns of use of suppression resources are more complex than elsewhere in Spain.

Although similar to other variables, the combined region of northern Cantabria and Asturias showed an opposite pattern in Fire Load (resulting negligible) and Fire Type, with more resources being dispatched to surface fires. Surface fires create the most relevant problems in these regions, where large tracts of shrub lands with the worst fire behavior have been created by abandonment of productive rangeland. Moreover, when compared with the nearby Galicia, Cantabria-Asturias exhibits more topographic complexity and lower forest property fragmentation, which favors lower transmittance of fire to tall forests (Rodriguez LA, Head of Prevention and Training of the Emergency Service of Asturias, pers. comm.). Castile and Leon showed a pattern similar to Galicia, but with lower influence of the Fire Load variable.

The individual patterns of Mediterranean regions were completely different, with Burned Area playing a major role in Extremadura and Andalusia. The relation between Burned Area and resources (both TUs and AUs) was stronger in southern Spain than in other regions. This finding may be explained by the fact that population density in the other regions is higher, therefore availability of local firefighting resources (especially personnel) is also higher.

Interestingly, daily fire load was not relevant in central-southern and eastern Spain. Fire Load did not imply a reduction in firefighting resources deployed to large, 100 ha+ fires in four of these regions. This finding may indicate that the occurrence threshold (number of fires) above which available resources are under duress may not yet have been reached, and that the national model is influenced by the high number of fires in NW Spain.

Some regional differences should be expected as different fire regimes in Atlantic (NW Spain) and Mediterranean Spain have been identified in previous studies (Verdu et al. 2012, Cardil \& Molina 2013, Moreno et al. 2014), and agencies naturally adjust their deployment protocols to the differ- ent ignition and propagation conditions and the values at risk. Resource use in large fires in the Mediterranean areas was substantially above the Spanish average. Lower resource use in the Atlantic likely indicated that burning conditions were not as extreme as in the Mediterranean (assuming no budgetary restrictions for either regions in 1998-2008). However, the influence of fire load in three regional models in the northwest, and very especially in Galicia, proved that the occurrence of multiple fires reduced available resources for large fires in these Spanish regions.

Management implications for regions with high fire occurrence need to be considered in our current scenario of a full suppression policy. If fire load is high, temporal constraints in use may occur, meaning that late-arrival fires will use fewer resources or none. When these constraints are in place, there is the possibility of improving the efficiency by training fire managers in advanced analysis of fire behavior and meteorology (Molina et al. 2010) and by optimizing the selection and distribution of resources (Martin-Fernandez et al. 2002, Rodriguez-Silva 2007), even leaving lower priority fires watched but unattended. And when fire load is high, social preventive action is essential (Raftoyannis et al. 2014).

In the future, we can expect worse fire danger conditions in all regions, a more complex WUI environment and constrained budgets (García-Rey et al. 2014, Liang et al. 2008, Raftoyannis et al. 2014), leading to the conclusion that new management strategies are required not only for Spain, but also for other Mediterranean countries with similar conditions (Mendes 2010). The potential impact on budgets should be carefully evaluated (Gebert \& Black 2012) and anticipated. Environmental conditions and fire behavior factors that would influence deployment, firefighting strategies and techniques could not be included in our models because they were not available in the official Spanish fire database, but they should be included in future work. Some recent extreme behavior fires have already offered reduced opportunities for fire suppression, being beyond suppression capacity (Molina et al. 2010, Cardil et al. 2014). The current pattern of adding suppression resources when fires grow in size or duration will not be the solution for future fire control, especially if resources are increasingly limited by higher human risk and lower budgets. It may be advisable to revise the current policy of suppression of all fires, as other countries have done before (USA and Canada, for instance). The heterogeneous regional environmental and the managerial characteristics and fire regimes (Moreno \& Chuvieco 2002) make fire prevention the focus for the future control of forest fires (Fernandes et al. 2013). Forest and fire prevention management alternatives for safer landscapes, including reduced fuel hazards arising from technical use of fire (Cassagne et al. 2011, Ager et al. 
2013, Fernandes et al. 2013) and information and education campaigns (Raftoyannis et al. 2014), should be a priority for Spain.

\section{Conclusions}

ANNs were successfully applied to model regional patterns of firefighting resource deployment in Spain. Our models suggested that Spanish agencies generally respond to large fires by adding more resources as the fires grow either in size or duration, but in some regions (especially those in NW Spain) multiple-fire situations divert resources from their use on large fires. However, national level analyses may mask the fact that trends of regional firefighting resources differ across Spain. Efficiency can be improved by training decision makers on advanced analysis of fire behavior and meteorology, but in the future we can expect worse danger conditions, a more complex WUI environment and constrained budgets. The full suppression policy being applied should be reexamined. The current pattern of just adding suppression resources with extended fire duration or size will not be the solution for future fire control, thus fire prevention should be a priority for Spain.

\section{Acknowledgments}

The authors gratefully acknowledge the provision of historical fire occurrence data by the National Forest Fire Statistics database (EGIF), Ministry of Environment and Rural and Marine Affairs (MAGRAMA). We would also like to thank Mr. Antonio Muñoz (MAGRAMA) for increasing our understanding of fire suppression in Spain. We thank the University of Lleida and the Pau Costa Foundation for supporting this study through a partial grant to fund A.C.'s PhD studies. We gratefully acknowledge an Erasmus Mundus grant from EACEA to S.D. for her MSc thesis in European Forestry. Finally, we thank two anonymous reviewers for their useful comments that improved this manuscript.

\section{References}

Ager AA, Vaillant NM, McMahan A (2013). Restoration of fire in managed forests: a model to prioritize landscapes and analyze tradeoffs. Ecosphere 4: art29. - doi: 10.1890/ES13-00007.1

Alcázar J, Palau A, Vega-Garcia C (2008). A neural net model for environmental flow estimation at the Ebro River Basin, Spain. Journal of Hydrology 349: 44-55. - doi: 10.1016/j.jhydrol.2007. 10.024

Alexander ME, Cruz MG (2014). Chapter 9: crown fire dynamics in conifer forests. In: "Synthesis of Knowledge of Extreme Fire Behavior: Volume 2 for Fire Behavior Specialists, Researchers and Meteorologists". General Technical Report PNW-GTR, Pacific Northwest Research Station, USDA Forest Service, Portland, OR, USA. [in press]

Alonso-Betanzos A, Fontenla-Romero O, Guijarro-Berdiñas B, Hernández-Pereira E, Paz Andrade $M I$, Andrade $P$, Jiménez $E$, Legido Soto JL, Carballas T (2003). An intelligent system for forest fire risk prediction and fire fighting management in Galicia. Expert Systems with Applications 25: 545-554. - doi: 10.1016/S0957-4174 (03)00095-2

Calkin DE, Thompson MP, Finney MA, Hyde KD (2011). A real-time risk-assessment tool supporting wildland fire decision making. Journal of Forestry 109: 274-280. [online] URL: http:// www.ingentaconnect.com/content/saf/jof/2011/ 00000109/00000005/arto0005

Cardil A, Molina DM (2013). Large wildland fires in three diverse regions in Spain from 1978 to 2010. Forest Systems 22: 526-534. - doi: 10.5424/ fs/2013223-03899

Cardil A, Salis M, Spano D, Delogu G, Molina Terrén $D$ (2014). Large wildland fires and extreme temperatures in Sardinia (Italy). iForest 7 (3): 162-169. - doi: 10.3832/ifor1090-007

Cassagne N, Pimont F, Dupuy J-L, Linn RR, Marell A, Oliveri C, Rigolot E (2011). Using a fire propagation model to assess the efficiency of prescribed burning in reducing the fire hazard. Ecological Modelling 222: 1502-1514. - doi: 10.1016/j. ecolmodel.2011.02.004

Castellnou M, Larrañaga A, Miralles M, Molina DM (2010). Improving wildfire scenarios: learning from experience. Research Report No. 23, European Commission, EFI, Joensuu, Finland, pp. 121-133.

Chas-Amil ML, Touza J, Prestemon JP (2010). Spatial distribution of human-caused forest fires in Galicia (NW Spain). WIT Transactions on Ecology and the Environment 137: 247-258. [online] URL: http://www.cabdirect.org/abstra cts/20103231465.html

Corne SA, Carver SJ, Kunin WE, Lennon JJ, van Hees WWS (2004). Predicting forest attributes in Southeast Alaska using artificial neural networks. Forest Science 50: 259-276. [online] URL: http://www.ingentaconnect.com/content/ saf/fs/2004/00000050/00000002/arto0010

Debouk H, Riera-Tatche R, Vega-Garcia C (2013). Assessing post-fire regeneration in a Mediterranean mixed forest using LIDAR data and Artificial Neural Networks. Photogrammetric Engineering and Remote Sensing 79: 11-21. - doi: 10.14358/PERS.79.12.1121

Dimuccio LA, Ferreira R, Cunha L, Campar de Almeida A (2011). Regional forest-fire susceptibility analysis in central Portugal using a probabilistic ratings procedure and artificial neural network weights assignment. International Journal of Wildland Fire 20: 776-791. - doi: 10.1071/WFogo83

Donovan GH, Rideout DB (2003). A reformulation of the cost plus net value change $(\mathrm{C}+\mathrm{NVC})$ model of wildfire economics. Forest Science 49: 318-323. [online] URL: http://www.ingenta connect.com/content/saf/fs/2003/00000049/00 $000002 /$ artoo015

Dupuy JL (2009). Fire start and spread. In: "Living with Wildfires: What Science Can Tell Us" (Birot $\mathrm{Y}$ ed). Discussion paper 15, European Forest Institute, Joensuu, Finland, pp. 27-31.

FahIman SE, Lebiere C (1990). The cascade-correlation learning architecture. In: "Advances in Neural Information Processing Systems. 2" (Touretzky ed), Morgan Kaufmann, S. Francisco, CA, USA, pp. 524-532 - [online] URL: http:// citeseerx.ist.psu.edu/viewdoc/summary?doi=10. 1.1.31.3071
FAO (2013). State of Mediterranean Forests 2013. FAO, Rome, Italy, pp. 174. [online] URL: http:// www.fao.org/docrep/017/i3226e/i3226e.pdf Fernandes PM, Davies GM, Ascoli D, Fernández $C$, Moreira F, Rigolot E, Stoof CR, Vega JA, Molina D (2013). Prescribed burning in southern Europe: developing fire management in a dynamic landscape. Frontiers in Ecology and the Environment 11 (s1): e4-e14. - doi: 10.189o/ 120298

Finney MA, Grenfell IC, McHugh CW (2009). Modeling containment of large wildfires using generalized lineal mixed-model analysis. Forest Science 55: 249-255. [online] URL: http:// www.ingentaconnect.com/content/saf/fs/2009/ $00000055 / 00000003 /$ arto0007

Ganewatta G, Handmer J (2009). The cost effectiveness of aerial fire fighting in Australia". Technical Report No. A.09.01, Bushfire Cooperative Research Center CRC, Melbourne Australia.

García-Rey M, Ramírez V, Jarreta D (2014). Opacidad y recortes en el gasto contra los incendios forestales [Opacity and cuts in spending against forest fires]. Espana en Llamas, web site report. [online] URL: http://www.espanaen llamas.es/

Gebert KM, Black AE (2012). Effect of suppression strategies on federal wildland fire expenditures. Journal of Forestry 110: 65-73. - doi: 10.58 49/jof.10-068

Gebert KM, Calkin DE, Yoder J (2007). Estimating suppression expenditures for individual large wildland fires. Western Journal of Applied Forestry 22: 188-192. [online] URL: http://www. ingentaconnect.com/content/saf/wjaf/2007/00 000022/00000003/art00006

Gonzalez-Caban A (1986). Developing fire management mixes for fire program planning. Gen. Tech. Rep. PSW-88, Pacific Southwest Forest and Range Experiment Station, USDA Forest Service, Berkeley, CA, USA, pp. 8. [online] URL: http://www.treesearch.fs.fed.us/pubs/27055

Guan BT, Gertner G (1991). Modeling red pine tree survival with an artificial neural network. Forest Science 37: 1429-1440. [online] URL: http://www.ingentaconnect.com/content/saf/fs /1991/00000037/00000005/art00017

Hasenauer H, Merkl D, Weingartner M (2001). Estimating tree mortality of Norway spruce stands with neural networks. Advances in Environmental Research 5: 405-414. - doi: 10.1016/ S1093-0191(01)00092-2

Hilbert DW, Ostendorf B (2001). The utility of artificial neural networks for modelling the distribution of vegetation in past, present and future climates. Ecological Modelling 146: 311327. - doi: 10.1016/S0304-3800(01)00323-4

Hunter TP (1981). Initial attack time and the influence of multiple fires. In: Proceedings of the Meeting "Computer modelling: its application in fire management" (Lotan JE ed). Salt Lake City (UT, USA) 20-22 Oct 1981. Intermountain Fire Council, Logan, UT, USA pp. 157-173.

Islam KMS, Martell DL (1998). Performance of initial attack airtanker systems with interacting bases and variable initial attack ranges. Canadian Journal of Forest Research 28: 1448-1455. doi: 10.1139/×98-127

Jutras P, Prasher SO, Mehuys GR (2009). Prediction of street tree morphological parameters 
using artificial neural networks. Computers and Electronics in Agriculture 67: 9-17. - doi: 10.1016/ j.compag.2009.02.008

Karouni A, Daya B, Chauvet P (2014). Applying decision tree algorithm and neural networks to predict forest fires in Lebanon. Journal of Theoretical and Applied Information Technology 63: 282-291.

Kaval P (2009). Perceived and actual wildfire danger: an economic and spatial analysis study in Colorado (USA). Journal of Environmental Management 234: 1-9. - doi: 10.1016/j.jenvman. 2008.12.009

Li LM, Song WG, Ma J, Satoh K (2009). Artificial Neural Network approach for modelling the impact of population density and weather parameters on forest fire risk. International Journal of Wildland Fire 18: 640-667. - doi: 10.1071/WF07136

Liang J, Calkin DE, Gebert KM, Venn TJ, Silverstein RP (2008). Factors influencing large wildland fire suppression expenditures. International Journal of Wildland Fire 17: 650-659. - doi: 10.1071/WF07010

Martin-Fernandez F, Martinez-Falero E, Perez JM (2002). Optimization of resources management in wildland fire suppression expenditures. International Journal of Wildland Fire 17: 650-659. Mees RM, Strauss D (1992). Allocating resources to large wildland fires: a model with stochastic production rates. Forest Science 38: 842-853. [online] URL: http://www.ingentaconnect.com/ content/saf/fs/1992/00000038/00000004/artoo 009

Mendes I (2010). A theoretical economic model for choosing efficient wildfire suppression strategies. Forest Policy and Economics 12: 329-329. - doi: 10.1016/j.forpol.2010.02.005

Mills TJ, Bratten FW (1988). Economic efficiency and risk character of fire programs, northern Rocky Mountains. Research Paper PSW-192, Pacific Southwest Forest and Range Experiment Station, USDA Forest Service, Berkeley, USA, pp. 52. [online] URL: http://gis.fs.fed.us/ psw/publications/documents/psw_rp192/psw_r p192.pdf

Mitrakis NE, Mallinis G, Koutsias N, Theocharis JB (2012). Burned area mapping in Mediterranean environment using medium-resolution multi-spectral data and a neuro-fuzzy classifier. International Journal of Image and Data Fusion 3: 299-318. - doi: 10.1080/19479832.2011.635604 Molina DM, Castellnou M, Garcia D, Salgueiro A (2010). Improving fire management success through fire behavior specialists. In: EFI Research Report no. 23 "Fire Paradox", Project no. FP6-018505, European Commission, Joensuu, Finland, pp. 105-119. [online] URL: http://www.ucm.es/data/cont/docs/530-2013-10- 15-efi_rr23.pdf\#page=117

Moreno MV, Chuvieco E (2002). Characterising fire regimes in Spain from fire statistics. International Journal of Wildland Fire 22: 296-305. doi: 10.1071/WF12061

Moreno MV, Conedera M, Chuvieco E, Pezzatti $G B$ (2014). Fire regime changes and major driving forces in Spain from 1968 to 2010. Environmental Science and Policy 37: 11-22. - doi: 10.1016/j.envsci.2013.08.005

NeuralWare (2009). NeuralWorks Predict, the complete solution for neural data modelling. User Guide, version 3.24, NeuralWare, Carnergie, PA, USA, pp. 397.

Padilla $M$, Vega-Garcia C (2011). On the comparative importance of fire danger rating indices and their integration with spatial and temporal variables for predicting daily human-caused fire occurrences in Spain. International Journal of Wildland Fire 20: 46-58. - doi: 10.1071/WFo9139 Paveglio TB, Carroll MS, Jakes PJ (2010). Alternatives to evacuation during wildland fire: exploring adaptive capacity in one Idaho community. Environmental Hazards: Human and Policy Dimensions 9: 379-394. [online] URL: http:// www.tandfonline.com/doi/abs/10.3763/ehaz.20 10.0060

Rachaniotis NP, Pappis CP (2006). Scheduling fire-fighting tasks using the concept of "deteriorating jobs". Canadian Journal of Forest Research 36: 652-658. - doi: 10.1139/x05-267

Raftoyannis $Y$, Nocentini S, Marchi E, Calama Sainz R, Garcia Guemes C, Pilas I, Peric S, Amaral Paulo J, Moreira-Marcelino AC, Costa-Ferreira M, Kakouris E, Lindner M (2014). Perceptions of forest experts on climate change and fire management in European Mediterranean forests. iForest 7: 33-41. - doi: 10.3832/iforo817006

Rodriguez-Silva $F$ (2007). Coste y eficiencia en las operaciones de extinción de los incendios forestales, fundamentos y herramientas para su estudio y análisis [Cost-efficiency in wildland FIRE management]. In: Proceedings of the " $44^{\text {th }}$ International Wildland Fire Conference - Wildfire 2007". Sevilla (Spain) 13-17 May 2007. Organismo Autónomo de Parques Nacionales, Ministerio de Medio Ambiente, Madrid, Spain.

Ruiz-Mirazo J, Martínez-Fernández J, Vega-García C (2012). Pastoral wildfires in the Mediterranean: understanding their linkages to land cover patterns in managed landscapes. Journal of environmental management 98: 43-50. - doi: 10.1016/j.jenvman.2011.12.017

Scrinzi G, Marzullo L, Galvagni D (2007). Development of a neural network model to update forest distribution data for managed alpine stands. Ecological Modelling 206: 331-346. - doi: 10.1016/j.ecolmodel.2007.04.001
Simard AJ, Young A (1978). AIRPRO - an air tanker productivity computer simulation model - application. Ontario Information Report FF-X69, Forest Fire Research Institute, Canadian Forest Service, Ottawa, Canada, pp. 23.

Vasconcelos MJP, Silva S, Tome M, Alvim M, Pereira JMC (2001). Spatial prediction of fire ignition probabilities: comparing logistic regression and neural networks. Photogrammetric Engineering and Remote Sensing 67: 73-81. [online] URL: http://www.asprs.org/a/publica tions/pers/2001journal/january/2001_jan_73-81.p df

Vasilakos C, Kalabokidis K, Hatzopoulos J, Matsinnos I (2009). Identifying wildland fire ignition factors through sensitivity analysis of a neural network. Natural Hazards 50: 125-143. doi: 10.1007/s11069-008-9326-3

Vázquez de la Cueva A, García del Barrio JM, Ortega Quero M, Sánchez Palomares O (2006). Recent fire regime in peninsular Spain in relation to forest potential productivity and population density. International Journal of Wildland Fire 15: 397-405. - doi: 10.1071/WF05071

Vega-Garcia C, Lee BS, Woodard PM, Titus SJ (1996). Applying neural network technology to human-caused wildfire occurrence prediction. Al Applications 10: 9-18.

Vega-Garcia C, Chuvieco E (2006). Applying local measures of spatial heterogeneity to LandsatTM images for predicting wildfire occurrence in Mediterranean landscapes. Landscape Ecology 21: 595-605. - doi: 10.1007/s10980-005-4119-5

Velez R (2000). La defensa contra incendios forestales: fundamentos y experiencias [Wildland fire management: principles and experience]. McGraw-Hill publishing, Madrid, Spain, pp. 800. [in Spanish]

Vélez R (2009). Forest fires in the Mediterranean Basin. In: Proceedings of the " 3 rd International Symposium on Fire Economics, Planning and Policy: Common Problems and Approaches" (González-Cabán A ed). General Technical Report PSW-GTR-227, Pacific Southwest Research Station, USDA Forest Service, Davis, CA, USA, pp. 1-7. [online] URL: http://www.cabdirect.org/ abstracts/20113108261.html

Verdu F, Salas J, Vega-Garcia C (2012). A multivariate analysis of biophysical factors and forest fires in Spain, 1991-2005. International Journal of Wildland Fire 21: 498-509. - doi: 10.1071/WF11100

Werbos PJ (1994). The roots of backpropagation: from ordered derivatives to neural networks and political forecasting. John Wiley \& Sons Inc, New York, USA, pp. 319. [online] URL: http://books.google.com/books?id=WdR3OOM $2 \mathrm{~g} \mathrm{BwC}$ 